\title{
Ruptured Distal Accessory Anterior Cerebral Artery Aneurysm -Case Report-
}

\author{
Kazuhito MATSUZAKI, ${ }^{1}$ Masaaki UNO, ${ }^{1}$ Toshitaka FUJIHARA, ${ }^{1}$ \\ Takeshi MIYAMOTO, ${ }^{1}$ Kimihiko YOKOSUKA, ${ }^{1}$ Hiroyuki TOI, ${ }^{1}$ \\ Shunji MATSUBARA, ${ }^{1}$ and Kazuhiro HIRANO ${ }^{1}$
}

${ }^{1}$ Department of Neurosurgery, Kawasaki Medical School, Kurashiki, Okayama

\begin{abstract}
A 48-year-old man presented with an extremely rare aneurysm arising from an accessory anterior cerebral artery (ACA) manifesting as sudden onset of headache lasting for 5 days. Neurological examination on admission revealed no abnormalities. Computed tomography showed subarachnoid hemorrhage of the interhemispheric fissure and intraparenchymal hematoma of the left cingulate gyrus. Magnetic resonance and cerebral angiography revealed a saccular aneurysm of the distal portion of the accessory ACA classified as the bihemispheric type. Neck clipping of the aneurysm was performed via an interhemispheric approach 17 days after symptom onset. The patient made a good postoperative recovery without neurological deficit. Distal accessory ACA aneurysms tend to arise from the first bifurcation and supply parietal branches. The aneurysms tend to occur on the bihemispheric type of distal accessory ACA. Hemodynamic stress may contribute to formation or development of these aneurysms.
\end{abstract}

Key words: accessory anterior cerebral artery, distal anterior cerebral artery, anomalous anterior cerebral artery, aneurysm, subarachnoid hemorrhage

\section{Introduction}

Distal anterior cerebral artery (ACA) aneurysms account for $2.7 \%$ to $6.0 \%$ of all intracranial aneurysms, ${ }^{3,14)}$ and are frequently associated with vascular anomalies of the ACA including azygous, bihemispheric, and triplicated ACA. ${ }^{3,6}$, ${ }^{18,20)}$ The median artery of the corpus callosum (MACC), a median branch of the triplicated ACA originating from anterior communicating artery, supplies the septal nuclei, septum pellucidum, and upper portion of the column of the fornix. If the MACC develops and gives rise to the usual cortical branches of the ACA in addition to supplying the above-mentioned areas, it is defined as an accessory ACA.1) Two types of accessory ACA are recognized; unihemispheric and bihemispheric. Accessory ACA is relatively common, and is found in $3.3 \%$ to $15.0 \%$ of the population. ${ }^{1,2,7,11,13)}$ However, aneurysms of this vessel are extremely rare with only a few reported cases. We report a case of ruptured aneurysm arising from the distal portion of the accessory ACA.

\section{Case Report}

A 48-year-old man presented with sudden onset of headache, which had persisted for 5 days before he con-

Received January 24, 2011; Accepted May 2, 2011 sulted our hospital. Neurological examination revealed no abnormalities. Brain computed tomography (CT) on admission showed small subarachnoid hemorrhage in the interhemispheric fissure and hematoma of the left cingulate gyrus (Fig. 1). Magnetic resonance angiography showed the three branches of the ACA appeared to originate from a communication site, suggesting triplication of the ACA (Fig. 2). One of the three branches coursed distally, probably along the corpus callosum like the normal pericallosal arteries, and was considered to be an accessory ACA. An aneurysm was seen to arise from the distal portion of this accessory ACA (Fig. 2). Right carotid angiography showed the artery supplied the bilateral mesial parietal lobes, and no cortical branch was identified between the origin and the first bifurcation. The aneurysm measured $9 \mathrm{~mm}$ in maximum diameter and was located at the first bifurcation with a broad neck and bilobulated dome (Fig. 3). A small aneurysm of the right internal carotid artery was also found at the origin of the anterior choroidal artery (Fig. 3).

The patient underwent right frontal craniotomy extended across the midline and neck clipping of the aneurysm 17 days after the onset of symptoms. Postoperative CT detected no new abnormal density areas. Postoperative angiography showed complete obliteration of the aneurysm with preservation of the distal branches and clearly demonstrated the triplication of the ACA (Fig. 4). The 


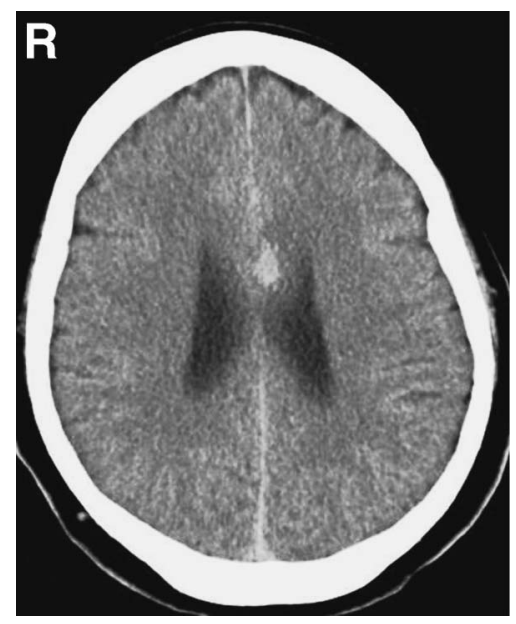

Fig. 1 Initial brain computed tomography scan revealing small subarachnoid hemorrhage in the interhemispheric fissure and intraparenchymal hematoma of the left cingulate gyrus.
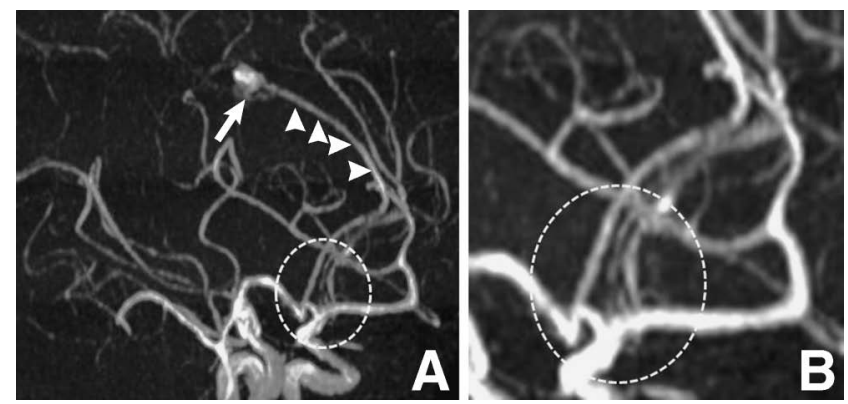

Fig. 2 A: Magnetic resonance angiogram showing triplication of the anterior cerebral artery (ACA) (dotted circle) and an aneurysm originating from the distal portion of the accessory ACA (arrow). Only one of the triplicated ACAs courses distally like the normal pericallosal arteries (arrowheads). B: Magnified image around the $A_{1}-A_{2}$ junction showing triplication of the ACA (dotted circle).

postoperative course was uneventful and the patient was discharged able to perform his usual daily activities.

\section{Discussion}

Nine cases of the aneurysms of the accessory ACA have

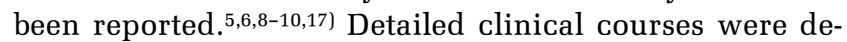
scribed in six of the previous cases, ${ }^{5,8-10,17)}$ and the present case, as listed in Table 1. Two of the aneurysms were unruptured and five were ruptured. Aneurysm size was recorded in four cases and ranged from 6 to $9 \mathrm{~mm}$ (mean $7.25 \mathrm{~mm}$ ). The aneurysms did not appear to be large in the three other cases. Recently, the anatomic features of distal ACA aneurysms of the entire postcommunicating segments were described with a detailed angiographic analysis of 101 patients. ${ }^{6)}$ The size of the distal ACA aneurysms appeared to depend on rupture status, as ruptured
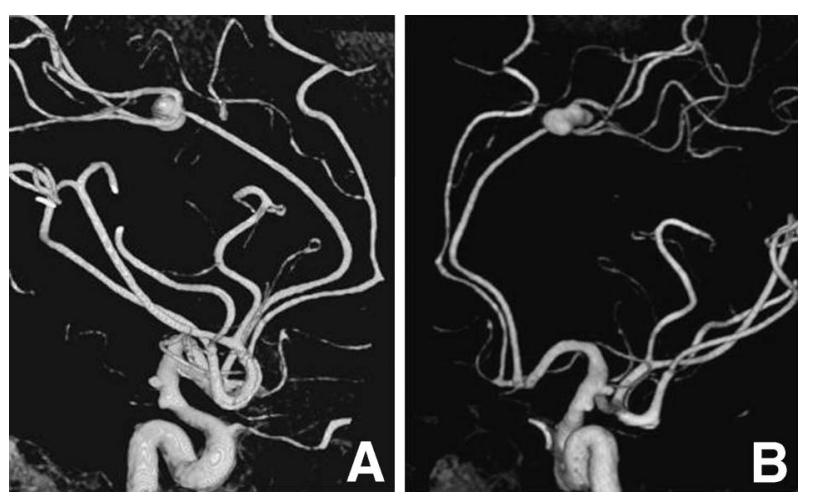

Fig. 3 Three-dimensional digital rotation angiograms, right anterior oblique (A) and left posterior oblique (B) projections, demonstrating a bihemispheric type of accessory anterior cerebral artery (ACA) and an aneurysm of the distal accessory ACA with a wide neck and bilobulated dome, as well as a right internal carotid artery aneurysm at the origin of the anterior choroidal artery.

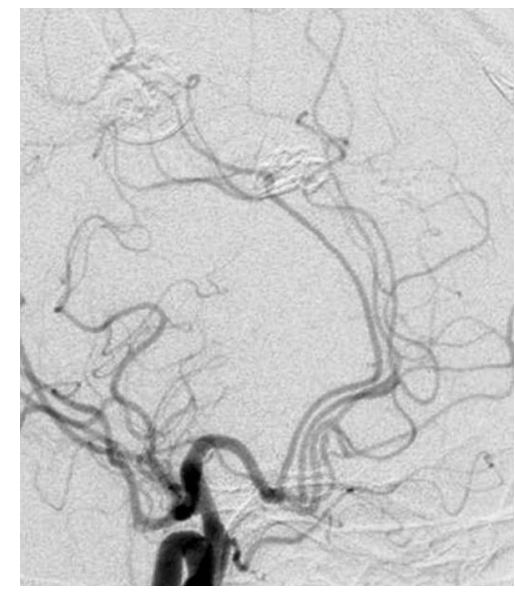

Fig. 4 Postoperative right carotid angiogram, right anterior oblique projection, showing triplication of the anterior cerebral artery (ACA) and complete obliteration of the distal accessory ACA aneurysm.

aneurysms were larger than unruptured ones, with mean sizes of $7.4 \mathrm{~mm}$ and $4.2 \mathrm{~mm}$, respectively. Thus, the size of the reported accessory ACA aneurysms seems similar to that of typical distal ACA aneurysms. However, no relationship between size and rupture status was observed in this small number of cases.

All accessory ACA aneurysms were located at sites corresponding to the $A_{4}$ or $A_{5}$ segment of the normal ACA and arose from the first branching sites of the cortical arteries. Furthermore, all accessory ACAs were the bihemispheric types, bifurcated at the $A_{4}$ or $A_{5}$ segment, and sent cortical branches to both hemispheres. No cortical branch was observed between the origin and bifurcation of these bihemispheric accessory ACAs. Therefore, we suggest that hemodynamic stress on the bifurcation 
Table 1 Summary of cases of distal accessory anterior cerebral artery (ACA) aneurysm with detailed clinical reports

\begin{tabular}{|c|c|c|c|c|c|c|c|c|}
\hline Author (Year) & $\begin{array}{l}\text { Age } \\
\text { (yrs)/ } \\
\text { Sex }\end{array}$ & Rupture & $\begin{array}{l}\text { Size of } \\
\text { aneurysm } \\
(\mathrm{mm})\end{array}$ & $\begin{array}{l}\text { Type of } \\
\text { accessory } \\
\text { ACA }\end{array}$ & Segment & $\begin{array}{c}\text { Multiplicity } \\
\text { of } \\
\text { aneurysm }\end{array}$ & Treatment & Outcome \\
\hline $\begin{array}{c}\text { Shimosegawa et al. } \\
(1985)^{17)}\end{array}$ & $66 / F$ & ruptured & 6 & bihem. & $\mathrm{A}_{5}$, bifurcation & - & clipping & excellent \\
\hline $\begin{array}{l}\text { Morioka et al. } \\
(1997)^{10)}\end{array}$ & $63 / \mathrm{M}$ & ruptured & NR & bihem. & $\mathrm{A}_{5}$, bifurcation & - & clipping & excellent \\
\hline$\underset{(2001)^{8)}}{\text { Mitsuyama et al. }}$ & $59 / \mathrm{M}$ & ruptured & NR & bihem. & $A_{5}$, bifurcation & - & clipping & excellent \\
\hline \multirow{2}{*}{$\begin{array}{l}\text { Kutsuna et al. } \\
(2006)^{5)}\end{array}$} & $66 / F$ & unruptured & 8 & bihem. & $\mathrm{A}_{5}$, trifurcation & - & clipping & excellent \\
\hline & $67 / F$ & unruptured & 6 & bihem. & $\mathrm{A}_{5}$, bifurcation & - & clipping & excellent \\
\hline $\begin{array}{l}\text { Morigaki et al. } \\
(2008)^{9)}\end{array}$ & $72 / \mathrm{F}$ & ruptured & NR & bihem. & $A_{5}$, trifurcation & - & $\begin{array}{l}\text { coiling followed } \\
\text { by clipping }\end{array}$ & good \\
\hline Present case & $48 / \mathrm{M}$ & ruptured & 9 & bihem. & $\mathrm{A}_{5}$, bifurcation & $+:$ ICA & clipping & excellent \\
\hline
\end{tabular}

bihem.: bihemispheric, F: female, ICA: internal carotid artery, M: male, NR: not recorded.

contributed to the formation or development of the aneurysm.9) This mechanism would also account for the frequent occurrence of accessory ACA aneurysm on the $\mathrm{A}_{4}$ or $\mathrm{A}_{5}$ segments, whereas $78.2 \%$ to $85.7 \%$ of distal ACA aneurysms are generally located on the $\mathrm{A}_{3}$ segment of the ACA. ${ }^{3,6)}$ In contrast, the $A_{4}$ and $A_{5}$ segments harbor only $6 \%$ to $7.6 \%$ of distal ACA aneurysms. ${ }^{3,6,14)}$

Distal ACA aneurysms are associated with not only anomalous ACAs but also other anomalies including vascular malformations and aneurysms. ${ }^{3,6,18,20)}$ Accessory ACA aneurysms appear to be less frequently associated with other vascular abnormalities. Concurrent cerebral aneurysm was found only in the present case, and no other vascular abnormalities were mentioned in other reported cases (Table 1). The initial treatment was coil embolization in one case of accessory ACA aneurysm, but the aneurysm neck could not be completely obliterated, so neck clipping of the aneurysm was performed 3 months after coil embolization. ${ }^{9)}$ Coil embolization of distal ACA aneurysms is considered to be more difficult than that of other aneurysms because of their small size, relatively wide neck, small caliber of the parent artery, and distal location. The complication rate is reported to be higher at $7-18 \% .4,12,15,16,19)$ In addition, these series contained many aneurysms in the $A_{2}$ or $A_{3}$ segments. ${ }^{4,12,15,16,19)}$ Accessory ACA aneurysms frequently arise from the $A_{4}$ or $A_{5}$ segments, so clipping appears to be more suitable than coiling for treatment of these aneurysms. In fact, treatment outcomes by clipping seem to be favorable as in typical distal ACA aneurysm (Table 1).

Distal accessory ACA aneurysms tend to arise from the $\mathrm{A}_{4}$ or $\mathrm{A}_{5}$ segments and to be bihemispheric. Hemodynamic stress appears to contribute to the formation or development of these aneurysms. Experience of more cases is required to further clarify the characteristics of accessory ACA aneurysms.

\section{References}

1) Baptista AG: Studies on the arteries of the brain: II-The anterior cerebral artery: Some anatomical features and their clinical implications. Neurology 13: 825-835, 1963
2) Gomes FB, Dujovny M, Umansky F, Berman SK, Diaz FG, Ausman JI, Mirchandani HG, Ray WJ: Microanatomy of anterior cerebral artery. Surg Neurol 26: 129-141, 1986

3) Hernesniemi J, Tapininaho A, Vapalahti M, Niskanen $M$, Kari A, Lukkonen M: Saccular aneurysms of the distal anterior cerebral artery and its branches. Neurosurgery 31: 994-999, 1992

4) Ketson P, White PM, Horribine L, Sellar R: The endovascular management of pericallosal artery aneurysms. J Neuroradiol 31: 384-390, 2004

5) Kutsuna M, Monden S, Watanabe K: [Two cases of distal anterior cerebral artery aneurysm associated with accessory anterior cerebral artery]. No Shinkei Geka 34: 193-200, 2006 (Japanese)

6) Lehecka M, Porras M, Dashti R, Niemelä M, Hernesniemi JA: Anatomic features of distal anterior cerebral artery aneurysms: A detailed angiographic analysis of 101 patients. Neurosurgery 63: 219-229, 2008

7) Marinkovic S, Milisavljevic M, Marinkovic Z: Branches of the anterior communicating artery: Microsurgical anatomy. Acta Neurochir (Wien) 106: 78-85, 1990

8) Mitsuyama T, Shimizu T, Kadowaki H: [A ruptured accessory anterior cerebral artery aneurysm]. No Shinkei Geka Journal 10: 461-464, 2001 (Japanese)

9) Morigaki R, Uno M, Matsubara S, Satoh K, Nagahiro S: Choreoathetosis due to rupture of a distal accessory anterior cerebral artery aneurysm. Cerebrovasc Dis 25: 285-287, 2008

10) Morioka M, Fujioka S, Itoyama $Y$, Ushio $Y$ : Ruptured distal accessory anterior cerebral artery aneurysm: Case report. Neurosurgery 40: 399-402, 1997

11) Nathal E, Yasui N, Sampei T, Suzuki A: Intraoperative anatomical studies in patients with aneurysms of the anterior communicating artery complex. J Neurosurg 76: 629-634, 1992

12) Nguyen TN, Raymond J, Roy D, Chagnon M, Weill A, IancuGontard D, Guilbert F: Endovascular treatment of pericallosal aneurysms. J Neurosurg 107: 973-976, 2007

13) Ogawa A, Suzuki M, Sakurai Y, Yoshimoto T: Vascular anomalies associated with aneurysms of the anterior communicating artery: Microsurgical observations. J Neurosurg 72: 706-709, 1990

14) Ohno K, Monna S, Suzuki R, Masaoka H, Matsushima $Y$, Hirakawa K: Saccular aneurysms of the distal anterior cerebral artery. Neurosurgery 27: 907-913, 1990

15) Pandey A, Rosenwasser RH, Veznedaroglu E: Management of distal anterior cerebral artery aneurysms: a single institu- 
tion retrospective analysis (1997-2005). Neurosurgery 61: 909-917, 2007

16) Pierot L, Boulin A, Castaings L, Rey A, Moret J: Endovascular treatment of pericallosal artery aneurysms. Neurol Res 18: 49-53, 1996

17) Shimosegawa $Y$, Takahashi A, Ohmura T: [Ruptured cerebral aneurysm of median artery of corpus callosum (accessory anterior cerebral artery): Case report]. No Shinkei Geka 13: 579-583, 1985 (Japanese)

18) Steven DA, Lownie SP, Ferguson GG: Aneurysms of the distal anterior cerebral artery: Results in 59 consecutively managed patients. Neurosurgery 60: 227-234, 2007

19) Waldenberger P, Petersen J, Chemelli A, Schenk C, Gruber I,
Strasak A, Eisner W, Beer R, Glodny B: Endovascular therapy of distal anterior cerebral artery aneurysm - an effective treatment option. Surg Neurol 70: 368-377, 2008

20) Wisoff JH, Flamm ES: Aneurysms of the distal anterior cerebral artery and associated vascular anomalies. Neurosurgery 20: 735-741, 1987

Address reprint requests to: Kazuhito Matsuzaki, MD, Department of Neurosurgery, Kawasaki Medical School, 577 Matsushima, Kurashiki, Okayama 701-0192, Japan.

e-mail: mkazuhito@hotmail.com 